\title{
MODELING ENERGY CONSUMPTION FOR THE GENERATION OF MICROFIBRES FROM BLEACHED KRAFT PULP FIBRES IN A PFI MILL
}

\author{
Ayan Chakraborty, ${ }^{\mathrm{a}}$ Mohini M. Sain, ${ }^{\mathrm{a}, \mathrm{b}^{*}}$, Mark T. Kortschot ${ }^{\mathrm{a}}$ and Subrata B.Ghosh ${ }^{\mathrm{b}}$ \\ The objective of this paper is to model the energy consumed in \\ generating cellulose microfibres, $1 \mu \mathrm{m}$ in diameter, as reinforcing agents, \\ by refining bleached softwood kraft pulp in a PFI mill. An average initial \\ fibre diameter of $13 \mu \mathrm{m}$ was assumed. 125,000 revolutions in a PFI mill \\ was found to produce a high yield of fibres $1.3 \mu \mathrm{m}$ in diameter, and the \\ minimum refining energy needed to reduce the fibre diameter to $1.3 \mu \mathrm{m}$ \\ was estimated as $1875 \mathrm{~kJ}$ for each $24 \mathrm{~g}$ charge in the PFI mill. Since \\ elastic deformation of the fibres was found to be negligible, the size \\ reduction was assumed to follow Rittinger's Law. This gave a Rittinger's \\ constant of $28 \mathrm{~J} . \mathrm{m} / \mathrm{kg}$ for the given system. Using this value of Rittinger's \\ constant, the energy required to generate microfibres $1 \mu \mathrm{m}$ in diameter \\ was predicted as $2480 \mathrm{~kJ}$ for each $24 \mathrm{~g}$ charge in the PFI mill. It was \\ deduced that microfibres generated in this way would cost a minimum of \\ $\$ 2.37$ per kilogram. Hence even this relatively inefficient method of \\ grinding would not be prohibitively expensive, provided the resulting \\ microfibres can be used as high quality reinforcements.
}

Keywords: cellulose microfibres, reinforcing agents, refining, PFI mill, Rittinger's Law

Contact information: a: Department of Chemical Engineering and Applied Chemistry, University of Toronto, 200 College Street, Toronto, Ontario, Canada M5S 3B3; b: Faculty of Forestry and Centre of Biocomposites and Biomaterials Processing, University of Toronto, 33 Willcocks Street, Toronto Ontario, Canada M5S 3E5; *Corresponding author: m.sain@utoronto.ca

\section{INTRODUCTION}

There is widespread interest in the production and use of micro- and nano-scale fibres for use as reinforcing agents. This trend originated with the production of nanoscale clay particles by researchers at Toyota, and has been accelerated because of the more recent introduction of carbon nano-tubes. There is also a great deal of interest in producing nano-scale cellulosic fibres from wood pulp and agricultural by-products; however, reliable and economical processes for doing this have yet to be developed.

In the present study, we examine the possibility of using refining as a method to generate microfibres $1 \mu \mathrm{m}$ in diameter from wood pulp fibres of approximately $13 \mu \mathrm{m}$ diameter. Such microfibres with high aspect ratio (length/diameter) would have the potential to act as excellent reinforcing agents in polymers. Refining is a specialized method of grinding fibres used in the pulp and paper industry; it is used in mechanical pulping, and also in developing fibre properties of pulp in papermaking. In a refiner, a dilute pulp suspension is forced through a gap between two surfaces moving rapidly relative to each other. Of these two surfaces, at least one has bars with sharp edges. 
Although this attempt to generate microfibres through refining is novel, production of fines during mechanical pulping has been studied and reviewed extensively by various researchers (Brecht, Klemm 1953; Mohlin 1977; Corson 1980; Luukko and Paulapuro 1997; Luukko 1998; Courchene et al. 2002). Fines are defined by the Technical Association of the Pulp and Paper Industry (TAPPI) as "particles that will pass a round hole $76 \mu \mathrm{m}$ in diameter or a nominally 200 mesh screen". Therefore, fines include both fibrillar materials of submicron diameter and hundreds of microns long, as well as chopped fragments of fibres having diameters in the same range as the dimension of the mesh opening.

Fibre development during mechanical refining, and its effect on the fracture energy of paper sheets of different pulp mixes, has been studied in detail (Lidbrandt et al. 1980; Mohlin et al. 1995; Mohlin 1997; Hiltunen et al. 2000; Hiltunen et al. 2002). However, these studies looked into the effect of refining on the strength of the paper structure directly, rather than focusing on the generation of microfibres.

The process of delamination of fibre walls by beating and refining has been studied in considerable detail (Page et al. 1967). As elucidated by Karnis (1994), the forces acting on the fibres in refining are assumed to act along the fibre length. As a result, the fibres are peeled off the surface in refining, as opposed to being chopped off perpendicular to the fibre length. This mechanism suggests that fibre length remains unchanged. The paper further noted that microscopic observations substantiated the above assumption. However, in practice, there is some fibre shortening associated with refining. Models on such comminution of fibres have been developed by Roux and Mayade (1997), who examined the change of the mean fibre length during refining. In this model, the potential of fibre cutting under given conditions was predicted to be a function of the energy consumed by the solid phase and of the average impact intensity, i.e., the ratio between the net machine power and the "cutting" length of bars per unit time. Corte and Agg (1980) used a comminution model to compare the shortening rate of fibres in a disc refiner and a laboratory beater. They found that the disc refiner cuts longer fibres more rapidly than the short fibres, while the laboratory beater was found to cut long and short fibres at the same rate. Olson et al. (2003) found that the probability of a fibre being selected for cutting during refining is proportional to the applied energy and fibre length, and was independent of pulp consistency. Corson (1972) mathematically modeled the refining of wood chips into individual fibres using a comminution approach. This approach was more recently expanded by Strand and Mokvist (1989) to model the operation of a chip refiner employed in mechanical pulping of wood chips.

However, these studies all used comminution models to predict the cutting of fibres perpendicular to the fibre axis, rather than the peeling action assumed to be predominant in refining (Karnis, 1994). The objective in this present study, therefore, is to model the energy consumed in peeling of a cellulose fibre to yield microfibres of smaller diameter

To study the effects of refining of pulp on papermaking in a laboratory scale, a PFI mill is commonly used. The PFI mill is used to pulp beat fibres to increase fibre flexibility and improve the properties of the resulting handsheet. In the process, the refiner causes fibrillation generating fibres of smaller diameter, and also produces fines. 
The components of a PFI mill are shown in Fig. 1. During the operation of the PFI mill, the head containing the bars is pushed to one side of the casing, as shown in Fig. 1. As elaborated by Murphy (1962), the stock in a PFI mill is centrifuged against the wall of the mill house. It is carried around in a narrow band toward the beating gap where it converges with the moving bars of the roll. The mill house at that point forms a smooth bedplate. The fibres are subjected to impact by rotating bars against the bedplate. The action of any refiner is determined by shear and compression forces in the refining zone, and by their distribution on single fibres. These forces are more evenly distributed in a laboratory beater such as the PFI mill than in industrial refiners. In over-simplified terms, the beating action resembles a plunger moving down into the pulp mass (Watson, Phillips 1964). The primary effects of the beating process are:

(a) intra-fibre bond breaking (internal fibrillation)

(b) external fibrillation

(c) fibre cutting and the production of fines

Studies of handsheet properties and microscopic examination of fibres have shown that all these effects take place in a PFI mill (Stationwala et al. 1996).

The dynamics of a single bar are shown pictorially in Fig. 2. The forces applied to the fibres in the beating gap can be resolved into two components - the compression force normal to the bar surface directly due to the load, and a tangential stress due to the resistance of pulp to shear imposed by the relative motion between the roll and the housing. Although the terms "shear" and "compression" are used to describe two components, the compression of the fibres in the gap in itself may involve a small component of shear.

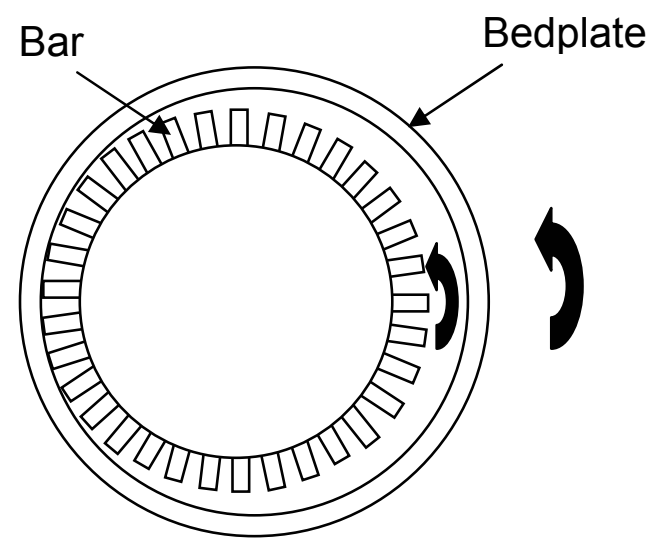

Fig. 1. Components of a PFI mill 


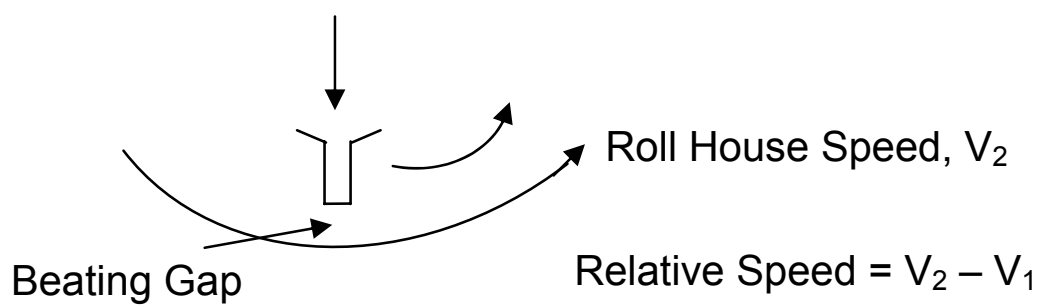

Fig. 2. Parameters related to the beating gap in a PFI mill

The aim of this work was to develop a quantitative model for microfibre generation from bleached kraft pulp through refining in a PFI mill. Theoretical studies on refining action noted earlier for other kind of refiners have estimated only the energy needed for fibre shortening. Thus, no work done so far provides any quantitative measure of the energy needed to generate microfibres from fibres by the reduction of diameter without any fibre shortening.

The goal of the refining modeled in this work is not merely to achieve better fibrillation on the cell wall surface, but also to separate microfibres as discrete entities with high aspect ratios. Therefore, the total energy imparted to the fibres needs to be much greater than what is usually employed in refining. This is substantiated by the conclusion drawn by Stationwala et al. (1996) that the peeling-off mechanism described earlier demands a relatively high amount of energy. Variations in the operating conditions of the PFI mill (load, consistency, temperature, nature of fibre, mill speed, etc.) may lead to an increase in the energy obtained in refining. But these variations alone may not be sufficient to substantially increase the generation of microfibres.

One simple way to substantially increase the energy imparted to the fibres is to keep the operation running for a much longer period of time. This implies that the number of revolutions employed has to be far greater than commonly used in laboratory conditions. As Kerekes (2001) noted, the extent of refining is most commonly expressed in terms of the number of revolutions. This forms the basis of the theory presented in this work, where bleached softwood kraft pulp was subjected to 125,000 revolutions in a PFI mill, as opposed to about 1,000 revolutions commonly used to study the effect of refining on fibre properties.

\section{EXPERIMENTAL DATA}

Developing a model for the energy consumption in generating microfibres requires some experimental data. These data form the basis for evaluating two of the assumptions used in the model development, as described in this section. 


\section{Generating Refined Fibres}

The experimental methods for generating these data are based on a process detailed by Chakraborty et al. (2005) for producing wood microfibres from bleached northern black spruce kraft pulp. In summary, $24 \mathrm{~g}$ of pulp fibres of $10 \%$ consistency was charged in a PFI mill, which was then rotated for 125,000 revolutions. In the original study, this refining step was followed by an additional stage of crushing the fibres under liquid nitrogen to obtain high yield of microfibres $1 \mu \mathrm{m}$ in diameter. For the purpose of the present work, however, the fibres were characterized right after the refining stage at the end of 125,000 revolutions of the PFI mill, before they were subjected to cryocrushing.

\section{Fibre Characterization}

SEM studies: A Hitachi S2500 Scanning Electron Microscopy (SEM) instrument was used to characterize the fibres after 125,000 revolutions. The refined fibres were dispersed in water to form a suspension of $0.1 \%$ fibres in water. A drop of this suspension was placed on the SEM stub, and allowed to dry before analyzing in the SEM. Each sample was gold coated, and a voltage of $10 \mathrm{kV}$ was used during imaging with the SEM. Samples of the bleached kraft pulp (BKP) were also prepared in the same manner.

25 such samples were prepared for both BKP and the refined fibres generated thereof, and the SEM images of 200 fibres of each were analyzed. Analysis of these images (Fig. 3) showed an average BKP fibre diameter of $13 \mu \mathrm{m}$. Moreover, image analysis revealed that more than $90 \%$ of the fibres generated in this way were in the range between a few nanometers and $2 \mu \mathrm{m}$ in diameter (Fig. 4). The distribution was centred around a diameter $1.3 \mu \mathrm{m}$. Therefore, for modeling purposes, an average final fibre diameter of $1.3 \mu \mathrm{m}$ was assumed at the end of 125,000 revolutions.

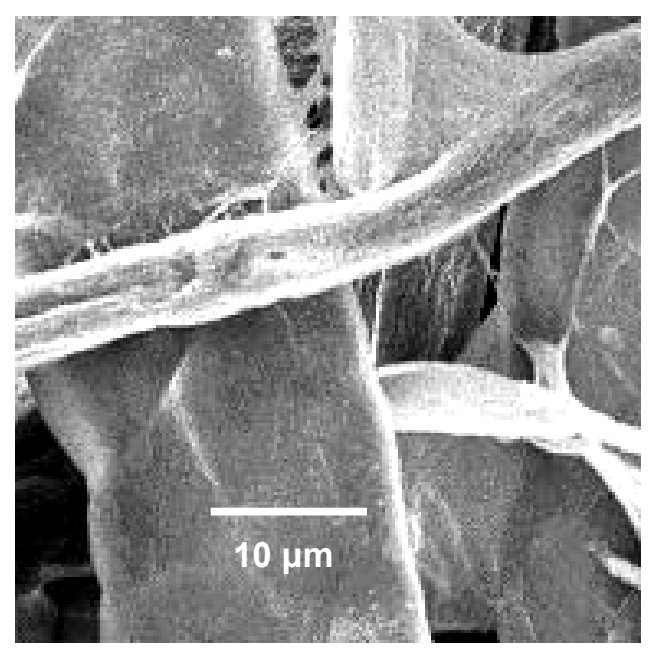

(a)

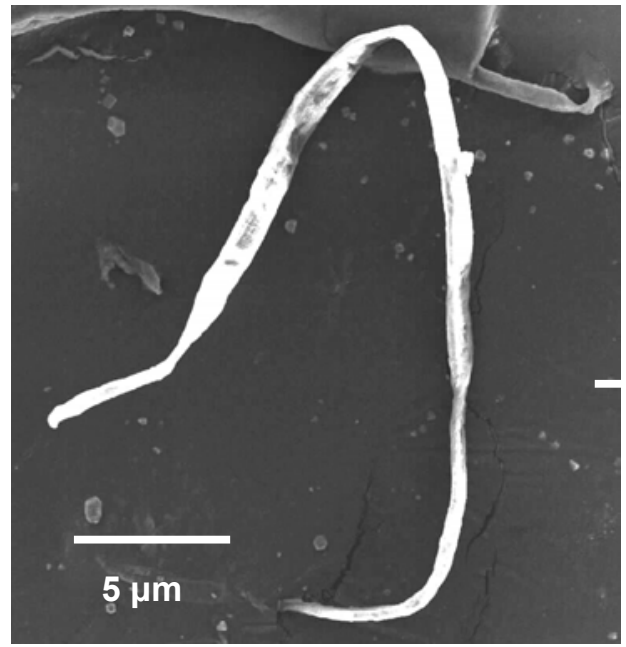

(b)

Fig. 3. Typical SEM images of (a) bleached kraft pulp (BKP) and (b) BKP after 125,000 revolutions in a PFI mill 


\section{Study of Tensile Property of Single Fibres}

The energy spent in elastic deformation of the fibres is critical in modeling the energy consumed in refining, for reasons described later. Therefore, the energy consumed in elastic deformation needed to be calculated as a fraction of the total energy consumed by the fibres before fracture. For this purpose, understanding of load-elongation (or stress-strain) behaviour of single fibres was important.

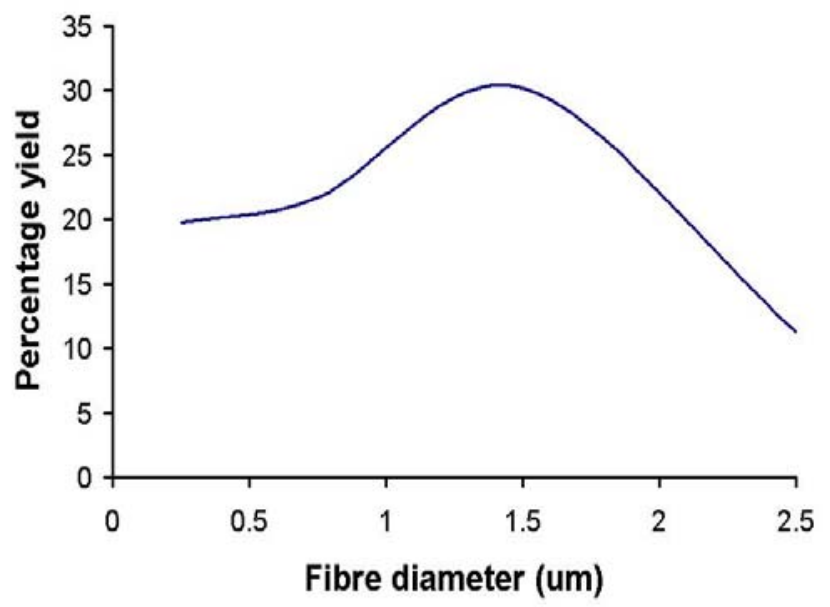

Fig. 4. Number yield of microfibres generated after refining

Previous studies (Page and EL-Hosseiny 1983) on tensile strengths of single pulp fibres indicated non-linear deformation behaviour especially with fibres having high micro fibril angle. The initial linear elastic region (following Hooke's law) was small compared to the total area under the stress-strain curve. In a recent study, Gilani (2006) also reported the tensile behaviour of isolated single pulp fibre. The study suggested that the nature of stress-strain curve and the fracture strength is strongly dependent on the isolation technique (mechanical or chemical) and on the micro fibril angle. While the mechanically isolated fibres failed at comparatively low strain in a rather brittle manner, chemically isolated (acid or alkali treated) fibres, which more closely resembles the BKP fibres used in this study, had large non-linear deformation region associated with high strain compared to small elastic deformation.

However, given the small length of $\sim 2 \mathrm{~mm}$ of the BKP fibres, it was practically impossible to clamp a single fibre in between the two clamps of a tensile tester. The strong tendency to twist in chemically isolated pulp fibres also add to uncertainties in the stress-strain results (Gilani 2006). Additional complications like were also reported in handling the short length pulp fibres.

Therefore, some other natural fibre had to be chosen that had similar properties as that of BKP fibres. The criteria that were matched were cellulose content and percentage crystallinity. These predominantly dictate the chemical and mechanical properties of the fibres. The cellulose content and crystallinity of BKP fibres were $90 \%$ and $55 \%$ respectively (Chakraborty et al. 2006). It was noted that the cellulose content of hemp fibres after acid and alkali treatment was $94 \%$, and the crystallinity was $55 \%$ (Bhatnagar 2004). 
Therefore, chemically treated single hemp fibres were used for tensile property studies. The acid and alkali treatments are described briefly as follows:

Acid treatment was performed to remove pectin and hemicellulose from hemp. Alkali treatment completes this removal process and also disrupts the lignin structure by separating the linkages between lignin and carbohydrates. For this purpose, hemp fibres were submerged in a $1 \mathrm{M}$ hydrochloric acid solution in a beaker at $80^{\circ} \mathrm{C} \pm 5^{\circ} \mathrm{C}$ for two hours with constant stirring. Subsequently, $2 \% \mathrm{w} / \mathrm{w}$ sodium hydroxide solution was added to the sample at $80^{\circ} \mathrm{C} \pm 5^{\circ} \mathrm{C}$ for two hours with constant stirring for better impregnation of alkali into the fibres. The treated fibres were then cooled and washed with abundant distilled water until it became neutral, and vacuum filtered.

Single fibres were isolated from the chemically treated hemp. The mechanical strength and modulus of the single fibres were analyzed with a Sintech-1 machine model 3397-36 in tensile mode with a load cell of $5 \mathrm{lb}$ using a gauge length of $15 \mathrm{~mm}$. The tensile tests were performed at a crosshead speed of $2.5 \mathrm{~mm} / \mathrm{min} .20$ chemically treated fibres were studied in this manner.

A typical stress-strain curve for a chemically treated hemp fibre is shown in Fig. 5. Energy taken up during tensile stress is given by the area under the stress-strain curve. The results indicated that the energy absorbed before breaking the fibres was predominantly in the non-linear deformation zone. The energy spent in elastic deformation, i.e., deformation up to the point where Hooke's Law holds good, ranged between $3 \%$ and $5 \%$ of the total energy.

Therefore, in view of the small proportion of energy transferred to the chemically isolated BKP fibre during elastic deformation, the elastic component of energy supplied to the fibres in tensile mode was neglected for modeling purposes.

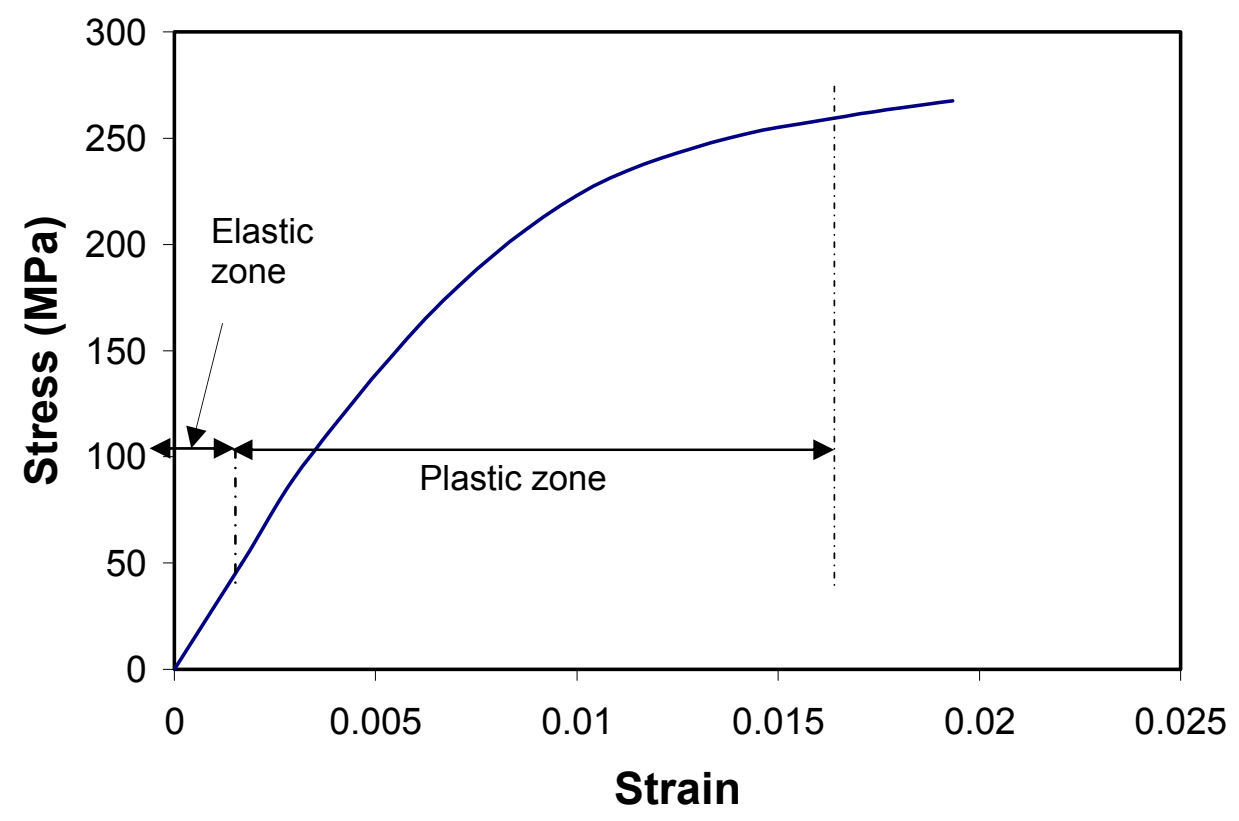

Fig. 5. Energy consumed during elastic and plastic deformations of chemically treated hemp fibres in tensile mode 


\section{MODEL ASSUMPTIONS}

In summary, the following assumptions were made in the model:

(i) Initial and final fibre diameters before and after refining are $13 \mu \mathrm{m}$ and 1.3 $\mu \mathrm{m}$ respectively.

(ii) The deformation of the fibres in the elastic zone is minimal. Therefore, the work of elastic deformation is negligible. This forms the basis of Rittinger's law, as discussed below.

(iii) A charge of $24 \mathrm{~g}$ of bleached kraft pulp of $10 \%$ consistency is used, which is the standard charge for a PFI mill (Tam Doo, Kerekes 1989).

\section{LAWS OF COMMINUTION}

Although comminution theory has been applied to the refining of fibres previously, there still exists substantial theory on comminution, correlating fibre size reduction to energy consumption, that has not been used by researchers studying pulp fibres. In this study, standard comminution theory has been used to determine the refining energy required to produce microfibres from bleached softwood kraft pulp fibres. For this purpose, some of the most common laws of comminution were considered.

\section{Rittinger's Law}

This law states that the energy input into a comminution process is proportional to the quantity of new surface produced. In the mathematical form

$$
E=\mathrm{C}\left(\mathrm{A}_{2}-\mathrm{A}_{1}\right)
$$

where $E$ = specific energy (i.e., energy per unit mass) input, $\mathrm{J} / \mathrm{kg}$ $A_{1}=$ initial specific surface (i.e., initial surface per unit volume), $\mathrm{m}^{-1}$ $\mathrm{A}_{2}=$ final specific surface, $\mathrm{m}^{-1}$ $\mathrm{C}=$ Rittinger's constant, J.m/kg

The value of $\mathrm{C}$ depends on the material being crushed. In this case, $\mathrm{C}$ is primarily a function of the hydrogen bond density among the different microfibres of cellulose.

\section{Kick's Theory and Bond's Theory}

Rittinger's formula only accounts for the decomposition of molecular bond forces. In practice, most materials elongate elastically before breakage, but the work of elastic deformation preceding fracture is neglected in Rittinger's formula. It has, however, been incorporated in other comminution laws, such as Kick's "volume" theory and by Bond's theory, referred to as "third theory" (Beke 1981). Kick's theory, however, considers only this elastic deformation energy, and neglects the work done in breaking a material into small particles. Bond's theory, on the other hand, accounts for the energy required in both elastic deformation, and the final breakage of the materials. 
It is worth mentioning that Kick's and Bond's theory are more appropriate with larger particles, while Rittinger's law is applied to fine grinding (Holdich 2002) as in PFI mill used in this study.

\section{Rationale for Using Rittinger's Law to Characterize Microfibre Generation from Fibres}

The energy imparted to the fibres during refining produces both elastic deformation and plastic deformation before breakage. However, the experiments on hemp discussed previously revealed that the energy for elastic deformation was negligible, and BKP fibre fracture occurs primarily by the decomposition of molecular bond forces (thereby creating new surfaces) in the plastic zone. Therefore, Rittinger's Law characterizes the process under investigation quite well. This is also substantiated by a study by Wisconsin (1957) who demonstrated experimentally that Rittinger's Law holds almost perfectly for ball mill beating of pulp.

\section{ENERGY AND COST ASSOCIATED WITH MICROFIBRE GENERATION}

The average initial diameter of each fibre of the starting material (BKP) is assumed to be $13 \mu \mathrm{m}$, as noted earlier. The refining action generated microfibres $1.3 \mu \mathrm{m}$ in diameter. Hence, the energy used in refining reduced the size of the fibres from $13 \mu \mathrm{m}$ to $1.3 \mu \mathrm{m}$.

\section{Energy Consumed by Fibres according to Rittinger's Law}

We consider a fibre of length $l, \mathrm{~m}$. For a fibre of diameter $\mathrm{d}, \mathrm{A}_{1}$ in equation (1) has a value of $\left[(\pi \mathrm{d} l) /\left(\pi \mathrm{d}^{2} l / 4\right)\right]=4 / \mathrm{d}=4 /\left(13 \times 10^{-6}\right) \mathrm{m}^{-1}=3.1 \times 10^{5} \mathrm{~m}^{-1}$. Similarly, $\mathrm{A}_{2}=$ $4 /\left(1.3 \times 10^{-6}\right) \mathrm{m}^{-1}=3.1 \times 10^{6} \mathrm{~m}^{-1}$.

Putting these values of $A_{1}$ and $A_{2}$ in equation (1) gives the specific energy to generate microfibres of $1.3 \mu \mathrm{m}$ diameter from fibres $13 \mu \mathrm{m}$ in diameter as

$$
E=\mathrm{C}\left(3.1 \times 10^{6}-3.1 \times 10^{5}\right)=27.9 \times 10^{5} \mathrm{C}, \mathrm{J} / \mathrm{kg}
$$

For the present work, the energy expressed in equation (2) is provided by a PFI mill. The charge in a PFI mill in this case consists of $24 \mathrm{~g}$ of fibres. Thus, for a charge of $24 \mathrm{~g}$ of fibres, equation (2) can be written as

$$
E^{\prime}=27.9 \times 10^{5} \mathrm{C} \times(24 / 1000), \mathrm{J}=66960 \mathrm{C}, \mathrm{J}
$$

where $E^{\prime}$ is the energy required for microfibre production for a sample size of $24 \mathrm{~g}$ of fibres.

\section{Energy Consumed by Fibres in Refining}

The operations of a PFI mill have been previously described by various researchers, but theoretical modeling relating the product properties to the operating parameters have been scarce. The most relevant studies in this direction have been 
performed by Kerekes and coworkers (reference?). The specific energy $(E)$ on pulp in a PFI mill is expressed as

$$
E=N I
$$

where $N=$ number of bar impacts per unit mass of fibres, and $I$ is the energy/impact, also called refining intensity (Welch and Kerekes, 1994)

Welch and Kerekes (1994) deduced that the specific energy consumption in PFI refining of bleached softwood kraft pulp lies within the range of 0.59 to $0.68 \mathrm{~J} / \mathrm{g}$.rev. In accordance with the approximate average value adopted by Kerekes (2001), a value of $0.63 \mathrm{~J} / \mathrm{g} \cdot \mathrm{rev}$ was assumed in the present case.

For a $24 \mathrm{~g}$ charge of BKP, and a number of revolutions $=N_{r}$, this gives the value of the total energy consumed as

$$
E^{\prime}=0.63 \mathrm{~J} / \mathrm{g} \cdot \mathrm{rev} \times 24 \mathrm{~g} \times N_{r} \text { rev., i.e, } E^{\prime}=15 N_{r}, \mathrm{~J}
$$

\section{Equating Refining Energy to Energy Consumed by Fibres According to Rittinger's Law}

Equating equations (3) and (5) gives

$$
\begin{aligned}
& 66960 \mathrm{C}=15 N_{r} \\
& \text { i.e., } N_{r}=4464 \mathrm{C}
\end{aligned}
$$

Hence, with the knowledge of the value of Rittinger's constant $\mathrm{C}$, the number of PFI revolutions to generate microfibres $1 \mu \mathrm{m}$ in diameter can be estimated.

\section{Net Energy Required for Microfibre Generation and Rittinger's Constant}

Considering 125,000 as the number of revolutions for generating fibres in the range of $1.3 \mu \mathrm{m}$ in diameter, equation (5) shows that $1875 \mathrm{~kJ}$ of energy is needed by a 24 $\mathrm{g}$ batch in a PFI mill to reduce the fibre diameter from $13 \mu \mathrm{m}$ to $1.3 \mu \mathrm{m}$.

Putting 125,000 as the number of revolutions in equation (7) gives a value of 28 J.m/kg for the Rittinger's constant.

\section{Energy Required to Generate Microfibres $1 \mu \mathrm{m}$ in Diameter}

Knowledge of the value of the Rittinger's constant for a given material makes it possible to deduce the energy required to reduce its diameter from any initial diameter to any final diameter. Therefore, if microfibres $1 \mu \mathrm{m}$ in diameter are to be generated by refining alone, the energy consumed in the process can be calculated by putting $1 \mu \mathrm{m}$ as the final diameter. This gives a value of $\mathrm{A}_{2}$ (i.e., 4/diameter) as $4 / 1 \times 10^{-6}=4 \times 10^{6}$.

Therefore equation (1) gives

$$
E=\mathrm{C}\left(4 \mathrm{X} 10^{6}-3.1 \mathrm{X} 10^{5}\right)=28(\mathrm{~J} . \mathrm{m} / \mathrm{kg}) X 36.9 \times 10^{5} \mathrm{~m}^{-1}=103.3 \mathrm{MJ} / \mathrm{kg}
$$


Hence, if microfibres $1 \mu \mathrm{m}$ in diameter are generated solely by refining in a PFI mill, each $24 \mathrm{~g}$ charge would consume an energy of about $2480 \mathrm{~kJ}$.

The number of revolutions needed for microfibre generation in a PFI mill may be calculated by putting the value of the energy per $24 \mathrm{~g}$ charge $\left(E^{\prime}\right)=2480 \mathrm{X} 10^{3} \mathrm{~J}$ in equation (5)

$$
2480 \times 10^{3}=15 N_{r} \quad \text { i.e., } N_{r}=165333
$$

Therefore, each $24 \mathrm{~g}$ of pulp charged in a PFI mill should be rotated for 165,333 revolutions to generate microfibres $1 \mu \mathrm{m}$ in diameter starting with fibres $13 \mu \mathrm{m}$ in diameter.

It should be recognized that the value of $103.3 \mathrm{MJ} / \mathrm{kg}$ obtained in equation (8) represents the energy requirement for microfibre generation from softwood bleached kraft pulp fibres through any size reduction process, not only for refining in a PFI mill.

\section{Cost of Microfibre Generation}

Considering the cost of electricity as 6 cents per kWh, i.e., 6 cents per $3600 \mathrm{~kJ}$, the cost of supplying 103.3 MJ of energy to the pulp is calculated as $\$ 1.72$. This implies that the generation of microfibres $1 \mu \mathrm{m}$ in diameter starting with bleached softwood kraft pulp costs $\$ 1.72 / \mathrm{kg}$. Moreover, the price of northern bleached softwood kraft pulp, although variable, is roughly in the range of $\$ 650$ per metric ton, i.e., 65 cents $/ \mathrm{kg}$. This indicates that the total cost of the cellulose microfibres is about $\$ 2.37 / \mathrm{kg}$, which is the sum of prices of the bleached kraft pulp, and of generating the microfibres thereof. This may be compared to the price of conventional polymers, most of which cost around $\$ 1 / \mathrm{kg}$. Since cellulose microfibres act as reinforcing agents, and contribute to an increase in mechanical properties of the matrix, a price of $\$ 2.37 / \mathrm{kg}$ of the reinforcing agents may be considered reasonable.

\section{CONCLUSIONS}

The energy required in generating microfibres $1 \mu \mathrm{m}$ in diameter from bleached kraft wood pulp was successfully modeled. The average diameter of each initial fibre before refining was considered as $13 \mu \mathrm{m}$. Rittinger's Law was used to characterize the energy requirement in generating the microfibres. Considering the experimental evidence that 125,000 revolutions in a PFI mill gave a high yield of fibres $1.3 \mu \mathrm{m}$ in diameter, Rittinger's constant for the given system was found out to be $28 \mathrm{~J} . \mathrm{m} / \mathrm{kg}$. Using this value of Rittinger's constant, the refining energy needed for generating microfibres $1 \mu \mathrm{m}$ in diameter was estimated as $103.3 \mathrm{MJ} / \mathrm{kg}$. For unit electricity cost of 6 cents per $\mathrm{kWh}$, this corresponds to a cost of $\$ 1.72 / \mathrm{kg}$, which brings the total cost of the microfibres to $\$ 2.37 / \mathrm{kg}$. Given that the price of conventional polymers is in the range of $\$ 1 / \mathrm{kg}$, the price of microfibres used as reinforcing agents may be feasible. 


\section{ACKNOWLEDGEMENTS}

The authors would like to acknowledge BIOCAP/NSERC Strategic Projects and Ontario Graduate Scholarship for providing financial assistance for this project.

\section{REFERENCES CITED}

Beke, B. (1981). "The process of fine grinding," Joint publication by: Martinus Nijhoff/Dr W. Junk Publishers, The Hague, The Netherlands, and Akademiai Kiado, Budapest, Hungary, pp. 10-12.

Bhatnagar, A. (2004). "Isolation of cellulose nanofibres from renewable feed stocks and root crops," Ph.D. thesis, Faculty of Forestry, University of Toronto.

Brecht, W., and Klemm, K. (1953). "The mixture of structures in a mechanical pulp as a key to knowledge of its technological properties," Pulp Pap. Mag. Can. 54(1), 72.

Chakraborty, A., Sain, M., and Kortschot, M. (2005). "Cellulose microfibrils: A novel method of preparation using high shear refining and cryocrushing," Holzforschung 59(1), 102-107.

Chakraborty, A., Sain, M., and Kortschot, M. (2006). "Reinforcing potential of wood pulp derived microfibres in PVA matrix", Holzforschung 60(1), 53-58.

Corson, S. R. (1972). "Probabilistic model of the disk refining process", Svensk Papperstidn. 75(2), 57-64.

Corson, S. R. (1980). "Fibre and fines fraction influence strength of TMP", Pulp Pap. Can. 81(5), 69-70, 73, 75-76.

Corte, H., and Agg, S. (1980). "Shortening of pulp fibres during beating", IPC Intern. Symp. Fundam. Concepts Refining 1980, Appleton, WI, 149-157.

Courchene, C. E., McDonough, T. J., and Page, D. H. (2002). "Effect of bleach plant processing on fiber strength", Tappi Fall Technical Conference and Trade Fair 2002, 93-101.

Gilani, M. S. (2006). "A micromechanical approach to the behaviour of single wood fibers and wood fracture at cellular level”, Ph.D. thesis, École Polytechnique Fédérale de Lausanne.

Hiltunen, E., Kettunen, H., Laine, J. E., and Paulapuro, H. (2000). "Effect of softwood kraft refining on a mechanical-chemical mixture sheet," Tappi J. 83(10), 67-75.

Hiltunen, E., Kettunen, H., Laine, J. E., and Paulapuro, H. (2002). "Effect of softwood kraft pulp refining on fracture behaviour of TMP-based paper," Appita 55(6), 494.

Holdich, R. (2002). "Fundamentals of particle technology", Midland information technology and publishing, UK, pp. 113-122.

Karnis, A. (1994). "The mechanism of fibre development in mechanical pulping," J. Pulp Paper Sci. 20(10), J280-J288.

Kerekes, R.J. (2001). "Characterization of refining action in PFI mills," PIRA $6^{\text {th }}$ International Conference, Toronto, Canada, 2001.

Lidbrandt, O., and Mohlin, U.-B. (1980). "Changes in fiber structure due to refining as revealed by SEM”, IPC Intern. Symp. Fundam. Concepts Refining 1980, 61-74. 
Luukko, K. (1998). "On the characterization of mechanical pulp fines," Paperi Puu 80(6), 411-448.

Luukko, K., and Paulapuro, H. (1997). "Mechanical pulp fines: effect of particle size and shape," Engineering \& Papermakers: Forming Bonds for Better Papermaking Conference 1997, 131-136.

Mohlin, U.-B. (1977). "Mechanical pulp properties - the importance of fines retention," Svensk Papperstidn. 80(3), 84-88.

Mohlin, U.-B. (1997). "Fiber development during mechanical pulp refining," J. Pulp Paper Sci. 23(1), J28-J3.

Mohlin, U.-B., and Miller, J. (1980). "Industrial refining - Effects of refining conditions on fiber properties," Refining 95: Third Intern. Refining Conference 1995, 13.

Murphy, D. C. (1962). "Mechanical factors in beating," Appita 16(1), 16-30.

Olson, J. A., Drozdiak, J., Martinez, M., Garner, R., Robertson, A. G., and Kerekes, R. (2003). "Characterizing fibre shortening in low-consistency refining using comminution model," Powder Technol. 129, 122-129.

Page, D. H., Seth, R. S., and DeGrace, J. H. (1967). "Delamination of fiber walls by beating and refining," Tappi 50(10), 489.

Page, D. H., and El-Hosseiny, F. (1983). "The mechanical properties of single wood pulp fibers. Part VI. Fibril angle and the shape of stress-strain curve," J. Pulp Paper Sci. 9, 99-100.

Roux, J. C., and Mayade, T. L. (1999). "Modeling of the particle breakage kinetics in the wet mills for the paper industry", Powder Technol. 105, 237-242.

Stationwala, M. I., Mathieu, J., and Karnis, A. (1996). "On the interaction of wood and mechanical pulping equipment. Part I: fibre development and generation of fines," $J$. Pulp Paper Sci. 22(5), J155-J160.

Strand, B. C., and Mokvist, A. (1989). "Application of comminution theory to describe refiner performance", J. Pulp Paper Sci. 15(3), J100-J105.

Tam Doo, P. A., and Kerekes, R .J. (1989). "The effect of beating and low-amplitude flexing on pulp fibre flexibility", J. Pulp Paper Sci. 15(1), J36-J42.

TAPPI, "Fines Fraction of Paper Stock by Wet Screening," Tappi Testing Method T 261 pm-80.

Watson, A. J., and Phillips, F. H. (1964). "Beating characteristics of the PFI mill III. Observations related to the beating mechanism", Appita 18(3), 84-102.

Welch, L. V., and Kerekes, R. J. (1994). "Characterization of the PFI mill by the Cfactor," Appita 45(5), 387-390.

Wisconsin, A., (1957). "Factors contributing to the strength properties of a sheet of paper," Project Report (Project 1513), 1-179.

Article submitted: Dec. 3, 2006; Resubmitted after format change: Dec. 5, 2006; First cycle of reviewing completed: January 9, 2007; Revised article submitted: April 20, 2007; Article accepted April 22, 2007; Published: April 24, 2007 